\title{
Optogenética e estimulação óptica neural: estado atual e perspectivas
}

\author{
Eddy Krueger*, Tiago Manczak, Edwing Martin Holguin Wilson, Wilson José da Silva, Percy Nohama
}

Resumo Ao longo dos últimos 50 anos, o uso da luz, em especial o laser, vem promovendo grandes avanços em diversas áreas da ciência e da tecnologia. Na última década o uso de estímulos ópticos no campo da biomédica tem despertado grande interesse no meio acadêmico e na indústria. Dois ramos que se destacam pelo seu crescimento são: a estimulação óptica direta e a optogenética. A primeira utiliza diferentes parâmetros da luz para adequar o efeito desejado na interação com o tecido biológico. A segunda faz uso de engenharia genética para tornar os tecidos biológicos sensíveis à luz. A estimulação neural por infravermelho (estimulação óptica direta) não necessita de contato direto com o tecido e apresenta maior seletividade especial se comparada à estimulação elétrica, mas tem a capacidade restrita de ativar (despolarizar) os neurônios. A optogenética, entretanto, pode ser utilizada para manipular o tecido neural tornando-o sensível à luz; sendo, então, possível despolarizar ou hiperpolarizar os neurônios codificados, assim como monitorar as ativações por meio de codificação de proteínas fluorescentes sensíveis à tensão elétrica. Tanto a técnica de estimulação óptica por infravermelho ou a técnica de optogenética, vêm sendo aplicadas apenas à modelos animais. Os resultados mostram, entretanto, que há grande viabilidade de aplicação da estimulação óptica em seres humanos. Futuramente, tais técnicas poderão substituir o atual padrão ouro para a ativação neural, a estimulação elétrica, em aplicações envolvendo doenças neurológicas específicas.

Palavras-chave Optogenética, Estimulação óptica neural, Fotoreceptores.

\section{Optogenetics and neural optical stimulation: current state and perspectives}

Abstract Within the last 50 years the light and specially the laser has fomented great advances in several areas of science and technology. During the past decade the use of optical stimuli in the biomedical research field have been of great interest for both academy and industry. Two research branches that can be highlighted due to its growth are: direct optical stimulation and optogenetic. The first one uses different parameters of light to optimize the desired effect on the tissue interaction. The other branch works with genetic engineering technics to make cells sensitive to light. The neural stimulation by infrared (direct optical stimulation) does not require direct contact with the tissue and has higher spatial selectivity when compared to electrical stimulation, but it has restricted ability to activate (depolarize) neurons. The optogenetic, however, can be used to manipulate the neural tissue depolarizing or hyperpolarizing encoded neurons, as well as monitor activations by encoding fluorescent proteins sensitive to voltage. The stimulation by infrared optical or optogenetic, has been applied only to animal models although there is a great possibility for human applications. In the future, it may even replace existing techniques such as electrical brain stimulation to treat specific neurological diseases.

Keywords: Optogenetic, Optical stimulation of neural tissue, Photoreceptors. 


\section{Extended Abstract}

\section{Introduction}

During the past decade the use of optical stimuli in the biomedical research field have grown substantially, due to advantages such as accuracy, noninvasiveness and lower prices. Two research branches that can be highlighted in this area are: direct neuron optical stimulation and optogenetic.

\section{Materials and Methods}

The search was conducted on the basis Wiley Online Library, ScienceDirect, SciELO, Biomed Central, Google Scholar, IEEE $X$ plore, IOP and books. The preferred language selected was English with the keywords: optogenetic, optical stimulation, infrared neural stimulation and photoreceptors. We performed the search for papers from 1979 to 2011. We discarded the papers that were not in accordance with the scope of this paper. After performing the search in the databases were read the abstracts and eliminated duplication, were extracted information about the following topics: optogenetics and optical stimulation of neural tissue.

\section{Results}

Four books and fifty one articles have heen used in this paper, collected from various search bases (Table 1) and over the years of 1979 to 2011 (Table 2).

\section{Discussion}

Neural optical stimulation uses different parameters of the light to optimize the desired effect on the tissue interaction, in this case, the production of action potential in neurons. Usually, the wavelength used in such applications is into the infrared spectra, greater than $770 \mathrm{~nm}$ (Cayce et al., 2010a; Duke et al., 2009; Harris et al., 2009; Izzo et al., 2006a, 2006b; Izzo et al., 2007; Wells et al., 2007b; Wininger et al., 2009). In neural optical stimulation (NOS) the light beam is applied directly over the neuron membrane, triggering the action potential. The possibility of controlling the action potential generation in a certain amount of neurons extends this application to the use in special prosthesis such as cochlear implants (Izzo et al., 2006a; Richter et al., 2008), visual implants (Kim et al., 2004), vestibular implants (Harris et al., 2009) and deep brain stimulation implants (Cayce et al., 2010b).

As in the electrical stimulation, in NOS, the higher the frequency, the lower the intensity of the light needed to depolarise neuronal cells (Cayce et al., 2010b). Wells et al. (2007b) studied the application of NOS using YAG laser $\left(\mathrm{Y}_{3} \mathrm{Al}_{5} \mathrm{O}_{12}\right)$ in periferical nerves assuring the results by histological tests. According to their results, the maximum pulse frequency of the YAG laser, for safe stimulation, is limited to $5 \mathrm{~Hz}$. Under this limit no tissue injury were detected. Another advantage of NOS is the selectivity of stimulation. This property allows to stimulate one specific nerve without interfering with adjacent nerves, that cannot be guaranteed by the usual electrical stimulation. This is important for applications such as visual implants, as those proposed by Kim et al. (2004) or the hearing implants proposed by Richter et al. (2008).

In optogenetics, on the other hand, the neurons are genetic engineered to make them sensitive to certain wavelengths (Liu and Tonegawa, 2010; Zhang et al., 2010). This is possible through the use of rhodopsins, the same proteins present in the photoreceptor cells of the retina. They can be extracted from microalgae or eubacterias and inserted in a virus, which in turn, modify the cells DNA. Some functions are then modified making neurons whether sensitive to light $(\lambda=960 \sim 470 \mathrm{~nm})$ (Andrasfalvy et al., 2010; Carter et al., 2010; Goold and Nicoll, 2010; Gunaydin et al., 2010; Kravitz et al., 2010) or with the hability to emit light $(\lambda=360 \mathrm{~nm}$ ) (Kötter et al., 2005).

The term optogenetic was first used by Deisseroth et al. (2006) in order to explain the use of light sensitive codificated proteins to monitor and control specific activities of neuronal circuits. The photoreceptors of rhodopsin were first isolated by Möglich and Moffat from the marine organism flagellate algae. Opsin genes can be inserted into neural tissue by viral vectors (Zhang et al., 2010). Those genes modify ionic (potassium and sodium) channels turning them light sensitive, that means, the potential of the cell membrane changes when it is exposed to light. Moreover, recently literature has come up with new possibilities, as researches Mutoh et al. (2010) developed animal models with biosensors using voltage sensitive fluorescent proteins (VSFP) extracted from marine animals like Ciona Intestinalis and Aequorea Victoria. These proteins can modify a neuron in such way that, as a synapse is generated, a light stimulus is also produced by the cell. Combining the light sensitive ionic channel and the VSFP in neuronal cells makes possible to produce a fully light controlled neuronal circuit.

\section{Conclusions}

Although optical stimulation by infra-red and optogenetics are relatively new fields of research, it has already been observed a wide expansion of researches applied, mostly, to animal models. However, the results presented in the work related to these themes show a broad perspective for human application, and may even come to replace the so-called ground truth methods (electrical stimulation) and propel new researches in the activation of neural circuits. 


\section{Introdução}

A utilização de tecnologia óptica é muito ampla e bem difundida na atualidade. O laser, por exemplo, causa diferentes alterações fotoquímicas, fototérmicas e fotomecânicas (Wells et al., 2007a) em tecidos biológicos conforme a variação de suas características (intensidade, tempo de aplicação, comprimento de onda). Ao longo dos anos, o laser popularizou-se tendo hoje inúmeras aplicações médicas e cirúrgicas em oftalmologia, odontologia, ginecologia, urologia, neurocirurgia, angioplastia e cardiologia, dermatologia, ortopedia, gastroenterologia, otorrinolaringologia e pneumologia (Niemz, 2004); além do uso em fisioterapia, como o laser $\mathrm{HeNe}$ $(630 \mathrm{~nm})$ na dermatologia (Ling e Wu, 2005), do laser GaAs (904 nm) na ortopedia (Naeser et al., 2002) e o laser AlGaInP (685 nm) em pontos de acupuntura (Valchinov e Pallikarakis, 2005).

Pesquisas recentes mostram duas novas aplicações de interação entre luz e tecidos biológicos, mais especificamente tecido neuronal. A primeira é a estimulação óptica, na qual um feixe de luz, geralmente na faixa do infravermelho (comprimento de onda $>770 \mathrm{~nm}$ ) (Cayce et al., 2010a; Duke et al., 2009; Harris et al., 2009; Izzo et al., 2006a, 2006b; Izzo et al., 2007; Wells et al., 2007b; Wininger et al., 2009) é aplicado diretamente ao neurônio deflagrando, assim, um potencial de ação (PA). O uso de estimulação óptica estende-se à fabricação de próteses especiais como implante coclear (Izzo et al., 2006a; Richter et al., 2008), visual (Kim et al., 2004), vestibular (Harris et al., 2009), e estimulação encefálica profunda (Cayce et al., 2010b).

Outra técnica para promover a interação entre neurônios e luz é a optogenética, que está embasada na introdução de um vírus no tecido nervoso com o DNA modificado (Liu e Tonegawa, 2010; Zhang et al., 2010). O vírus contém rodopsinas, proteínas presentes em fotorreceptores da retina que podem também ser extraídas de microalgas e eubactérias. Com essas proteínas, é possível manipular funções de células como os neurônios (Hegemann e Möglich, 2010), tornando-os sensíveis à luz para uma faixa compreendida entre 470 a $960 \mathrm{~nm}$ (Andrasfalvy et al., 2010; Carter et al., 2010; Goold e Nicoll, 2010; Gunaydin et al., 2010; Kravitz et al., 2010) ou fazendo com que emitam luz em um comprimento de onda $(\lambda)$ igual a $360 \mathrm{~nm}$ (Kötter et al., 2005).

\section{Materiais e Métodos}

A busca de informações foi realizada nas bases Wiley Online Library, ScienceDirect, Scielo, Biomed Central, Google Scholar, IEEE Xplorer, IOP e livros. $\mathrm{O}$ idioma de preferência selecionado foi o inglês com as palavras-chave: optogenetic, optical stimulation, infrared neural stimulation e photoreceptors. Seguindo o método retrospectivo, efetuou-se a procura de trabalhos com uma janela de tempo de 1979 a 2011. Foram descartados os trabalhos que não estavam de acordo com o escopo do artigo. Após a realização da busca nas bases de dados, foram lidos os abstracts e eliminadas as duplicações. Dos trabalhos selecionados, foram extraídas informações a respeito dos seguintes tópicos: optogenética e estimulação óptica neural.

\section{Resultados}

Todos os trabalhos selecionados versavam sobre: optogenética, estimulação neural óptica e assuntos afins, como fotoreceptor, potencial de ação, neuroanatomia, dentre outros. A Tabela 1 mostra os trabalhos utilizados e suas respectivas bases de pesquisa. A Tabela 2 mostra os artigos e livros divididos por ano.

\section{Discussão}

\section{Optogenética}

O termo optogenética (do inglês optogenetic) foi cunhado por Deisseroth et al. (2006) para se referir às proteínas codificadas que respondem à luz para monitorar e controlar a atividade específica de

Tabela 1. Quantidades de artigos e livros avaliados e as bases de pesquisa utilizadas.

Table 1. Amount of articles and books used and the research data bases.

\begin{tabular}{lccc}
\hline Base de pesquisa & Optogenética & Estimulação óptica & Assuntos afins \\
\hline Google acadêmico & 18 & 11 \\
Biomed Central & 1 & 2 \\
ScienceDirect & 6 & 1 & \\
Wiley Online Library & 1 & 5 \\
IOP & 1 & & \\
IEEE Xplorer & 1 & 1 & 1 \\
SciELO & & 3 \\
Livro & & \\
\hline
\end{tabular}


Tabela 2. Número de artigos e livros utilizados entre os anos de 1979 a 2011.

Table 2. Amount of papers and books used in the period of 1979 to 2011.

\begin{tabular}{cccc}
\hline Ano & Optogenética & $\begin{array}{c}\text { Estimulação } \\
\text { óptica }\end{array}$ & $\begin{array}{c}\text { Assuntos } \\
\text { afins }\end{array}$ \\
\hline 1979 & & & 1 \\
1993 & & & 1 \\
1996 & & & 1 \\
2002 & & 2 & 2 \\
2004 & & 4 & \\
2005 & 1 & 2 & 2 \\
2006 & & 5 & 1 \\
2007 & & 1 & 2 \\
2008 & 1 & 3 & 1 \\
2009 & 21 & 3 & 1 \\
2010 & 5 & & 1 \\
2011 & & & \\
\hline
\end{tabular}

circuitos neurais. Os fotorreceptores, amplamente utilizados na optogenética e também presentes na retina, são receptores neurais especiais que respondem à absorção de luz com uma mudança na atividade biológica como o potencial da membrana do neurônio (Möglich e Moffat, 2010). Esses fotorreceptores são formados por rodopsinas, proteínas contendo sempre dois terminais polares, basicamente um grupamento amina $\left(\mathrm{NH}_{2}\right)$ e outro carboxila $(\mathrm{COOH})$ (Hegemann e Möglich, 2010). Quando fótons incidem nos fotorreceptores localizados na retina, reações bioquímicas alteram o potencial elétrico da membrana celular. O bastonete, quando incidido por um fóton, transforma o 11-cis retinal (proveniente da rodopsina) (Kraft et al., 1993) em all-trans retinal, com uma reação em cascata proporcionada pela proteina $\mathrm{G}$ (guanosina trifosfato) (Hubbell e Bownds, 1979) no meio intracelular. Assim, ocorre a inibição dos canais de cátions da membrana, gerando hiperpolarização devido à diminuição da condutância dos íons $\mathrm{de}^{\mathrm{Na}^{+}}$ e Ca ${ }^{++}$(Baylor, 1996).

Os fotorreceptores de canais de rodopsina foram isolados primeiramente do organismo marinho flagellate algae (Möglich e Moffat, 2010). Genes de opsina podem ser introduzidos no tecido neural utilizando-se vetores virais (Zhang et al., 2010), os quais tornam canais de cátions, sódio e potássio (Mutoh et al., 2010), de neurônios sensíveis à luz podendo responder com alteração no potencial da membrana quando incididos por luz (Mutoh et al., 2010). A modificação gênica (Liu e Tonegawa, 2010) é realizada pela enzima Cre-recombinase (Gradinaru et al., 2010), sendo a despolarização da membrana celular decorrente da codificação dos genes microbianos de opsina (Hegemann e Möglich, 2010). A Figura 1 mostra os microorganismos utilizados para codificar os canais iônicos que respondem ao estímulo luminoso. O canal iônico codificado channelrhodopsin-2 (ChR2), como mostra a Figura 2, provém do microorganismo Chlamydomonas Reinhardtii. O channelrhodopsin-1 (VChR1) (Hegemann e Möglich, 2010) provém da Volvox Carteri e o canal halorhodopsin (NpHR) (Gradinaru et al., 2010) da estrutura microbiana Natronomonas Pharaonis.

Os canais codificados ChR2 e o canal VChR1 respondem ao estímulo luminoso, como mostra a Figura 3, com a abertura dos canais de cátions da membrana despolarizando-a (Hegemann e Möglich, 2010). O canal NpHR ativa a entrada de ânions na membrana gerando á hiperpolarização do meio intra celular (Gradinaru et al., 2010). O ChR2 tem sua ativação maximizada pela luz azul cujo comprimento de onda $(\lambda)$ é $470 \mathrm{~nm}$ (Zhang et al., 2010) e o canal VChR1 pela luz amarela ( $\lambda$ próximo de $590 \mathrm{~nm}$ ) (Mancuso et al., 2011). As faixas de comprimento de onda que respondem aos canais iônicos codificados (Zhang et al., 2010) ChR2, VchR1 e NpHR são mostrados na Figura 4.

Andrasfalvy et al. (2010) identificaram os parâmetros ótimos para a excitação focal de $\mathrm{ChR} 2$ a dois fótons. Desses parâmetros, destacam-se o comprimento de onda para uma faixa de $800 \mathrm{~nm} \leq \lambda \leq 960 \mathrm{~nm}$, para uma potência $(\mathrm{P})$ compreendida entre $0 \leq \mathrm{P} \leq 400 \mathrm{~mW}$. $\mathrm{O}$ pico de absorção para apenas dois fótons foi encontrado para $\lambda$ igual a $880 \mathrm{~nm}$. Em relação à potência, foi verificada uma relação não linear com o tempo de despolarização da célula, apresentando acima de $300 \mathrm{~mW}$ pouca variação $(<2 \mathrm{~ms})$ com o aumento de potência. Aumentando a duração do pulso sobre neurônios inibitórios (canais NpHR), não há um valor diferenciado do potencial de membrana hiperpolarizada (Andrasfalvy et al., 2010), pois a célula obedece à lei do efeito tudo ou nada (Bean, 2007).

Os canais de íons ChR2 tem uma constante de desativação de $\sim 12 \mathrm{~ms}$, e os canais de VChR1 tem uma constante de desativação de $\sim 120 \mathrm{~ms}$ (Zhang et al., 2010). Receptores conseguem transmutar sinais de flashes luminosos na faixa de milissegundos ( $\sim 12 \mathrm{~ms} \mathrm{a} \sim 120 \mathrm{~ms})$, para uma frequência de ativação (Fatv) compreendida entre 30 e $50 \mathrm{~Hz}$ (Zhang et al., 2010). Algumas células com canais ChR2 podem apresentar certas anomalias na resposta à luz como a não produção de potenciais evocados à frequências de estímulo acima de $40 \mathrm{~Hz}$, além de apresentarem a frequências mais baixas uma espícula extra para cada pulso individual (Gunaydin et al., 2010). Entretanto, novos receptores vêm sendo desenvolvidos e aperfeiçoados para a optogenética (Liu e Tonegawa, 2010). Gunaydin et al. 


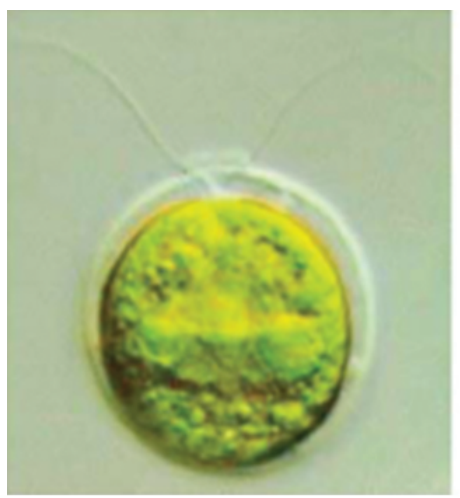

Chlamydomonas reinhardtii

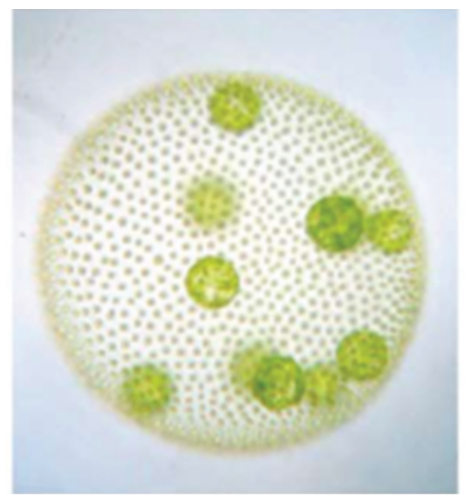

Volvox

carteri

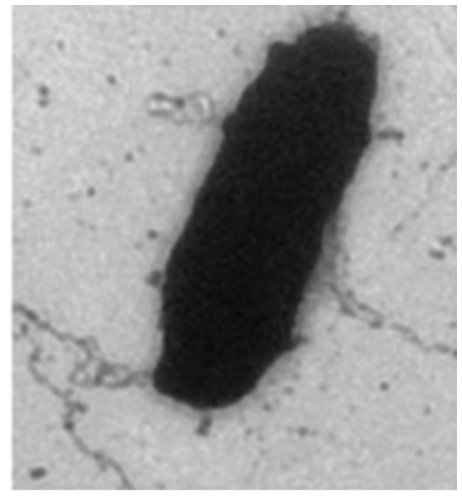

Natronomonas pharaonis

Figura 1. Imagem microscópica dos microorganismos utilizados para produzir canais iônicos codificados pela optogenética para responder a luz [adaptado de Zhang et al. (2010)].

Figure 1. Microscopic image of the microorganisms used to produce ion channels encoded by optogenetics to respond to light [adapted from Zhang et al. (2010)].

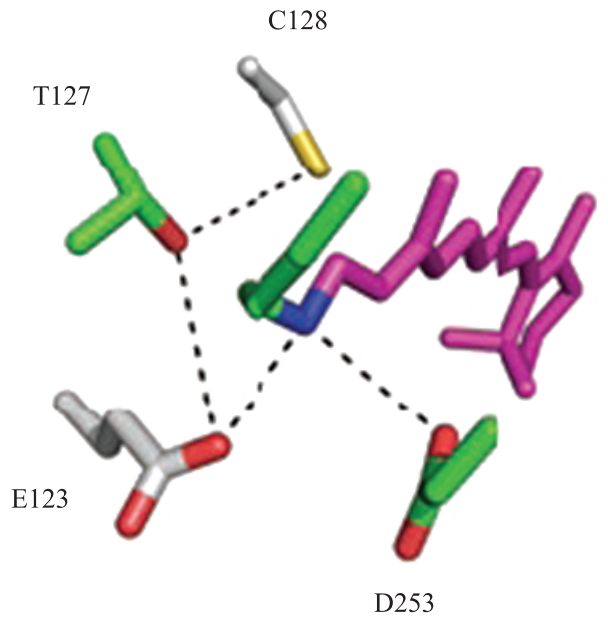

Figura 2. Modelo da estrutura do canal de rodopsina 2 (ChR2) [adaptado de Gunaydin et al. (2010)].

Figure 2. Model of the channelrhodopsin-2 structure (ChR2) [adapted from Gunaydin et al. (2010)].

(2010) codificaram o gene de opsina ChETA para trabalhar com frequências que atinjam até $200 \mathrm{~Hz}$, faixa de trabalho cinco vezes maior que os canais ChR2.

A optogenética pode ser utilizada na manipulação de mensageiros intracelulares secundários como a adenosina monofosfato cíclico (cAMP) e da Guanosina monofosfato cíclico (cGMP) (Ryu et al., 2010). Teh et al. (2010) desenvolveram o fotossensibilizador KillerRed que, exposta à luz branca ou a verde, estimula fortemente a interação bioquímica do oxigênio. Em baixos níveis, a ativação do oxigênio pode promover a mitose, mas em altos níveis provoca apoptose (morte celular). A utilização do KillerRed estende-se à simulação de patologias cardíacas, com a perspectiva de aplicação em tecido neoplásico (canceroso).

A optogenética é viável ainda para a estimulação da plasticidade neural, que envolve os sistemas de aprendizado e memória nas regiões cornos de Amon (CA) 1 e 3 do hipocampo (Gradinaru et al., 2010), com enorme viabilidade para futuras aplicações médicas (Fiala et al., 2010). A aplicabilidade da optogenética pode se estender à monitorização da atividade celular (movimentação de $\mathrm{Ca}^{++}$) dos astrócitos (Figueiredo et al., 2011), que são células do tecido conjuntivo (neuroglias) do sistema nervoso central e periférico (Haines, 2008; Machado, 2006). Como ilustrado na Figura 5, a optogenética ativa/inibe o neurônio com os canais codificados e consequentemente despolariza ou hiperpolariza os neurônios com os quais faz conexão, como se o neurônio fosse ativado/inibido fisiologicamente (Palmer, 2010).

Desenvolvimentos recentes na optogenética estão abrindo novas possibilidades para o campo da neurociência (Fiala et al., 2010; Zhang et al., 2010). Pesquisadores como Mutoh et al. (2010) vem trabalhando no ultimo decênio em cultura celular e em modelos animais com biosensores por meio de modificação gênica em proteínas fluorescentes sensíveis à tensão elétrica (do inglês voltage sensitive fluorescent proteins (VSFPs)). Quando o neurônio modificado gera uma sinapse, o mesmo responde com um estimulo luminoso. Para a Produção das VSFPs, são utilizadas modificações das proteínas de animais marinhos como a ascídia (Ciona intestinalis) e da água-viva (Aequorea Victoria) (Mutoh et al., 2010). As VSFPs tendem a ser monocromáticas como mostra 
a Figura 6, respondendo a um comprimento de onda de luz específico entre o vermelho e o azul.

Pode-se codificar neurônios com a ChR2 (que responde com a despolarização) e/ou com a NpHR (que responde com a hiperpolarização) e codificar neurônios adjacentes com VSFPs, assim, um estímulo pós sináptico pode ser expresso por um sinal luminoso (Mancuso et al., 2010) como mostra a Figura 7. Lee et al. (2010) aplicaram laser azul (comprimento de onda igual a $473 \mathrm{~nm}$ ) a $20 \mathrm{~Hz}$ (duração do pulso $15 \mathrm{~ms}$ ) no tálamo motor, onde foi evidenciada a ativação do córtex motor de ratos adultos, tendo sido o vírus implantado no córtex motor. Esses resultados mostram que utilizando as técnicas da optogenética é possível alterar as codificações das vias neurais, viabilizando a identificação de vias encefálicas.

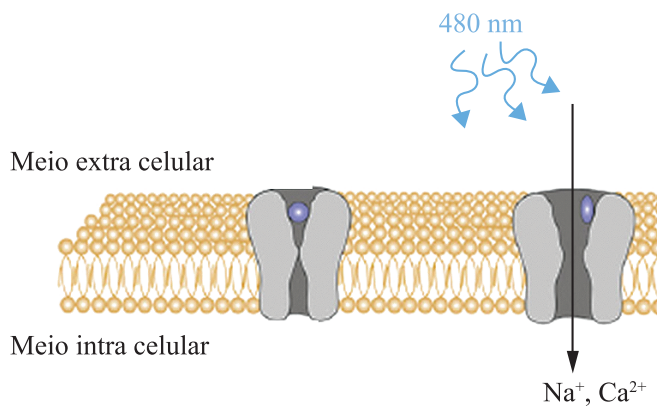

Figura 3. Canais de cátions codificados que respondem a fótons com a entrada de íons no meio intracelular e despolarização da membrana [adaptado de Fiala et al. (2010)].

Figure 3. Encoded cation channels responsive to photons by the entering of ions into the intracellular medium and membrane depolarization [adapted from Fiala et al. (2010)].

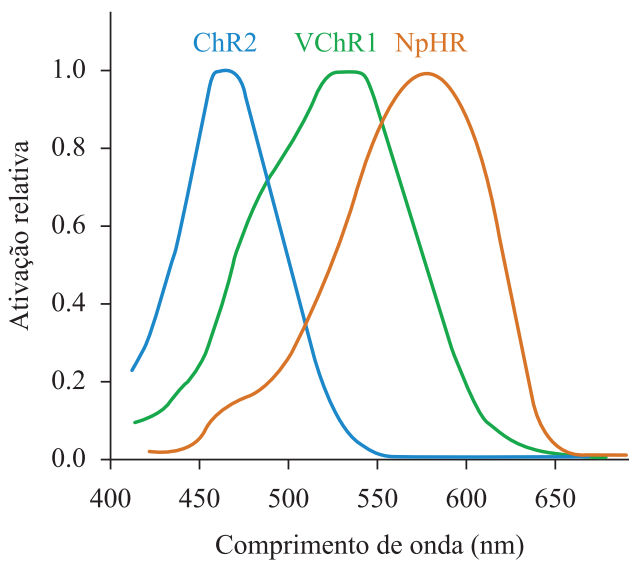

Figura 4. Comprimentos de onda que respondem aos canais iônicos codificados [adaptado de Zhang et al. (2010)].

Figure 4. Wavelengths that respond to the coded ion channels [adapted from Zhang et al. (2010)].
A técnica de ressonância magnética funcional BOLD (Blood oxygenation level dependent, dependente do nível de oxigênio no sangue) avalia a atividade neural (Lee et al., 2010). Mesmo sendo aplicada em modelo animal, a ressonância magnética com BOLD, em conjunto com a técnica de optogenética, mostra-se futuramente possível para determinação de mapas neurais em humanos (Palmer, 2010). As vias tálamo-corticais e cortiço-talâmicas são entrelaçadas, o que torna difícil o estudo das suas conexões. A optogenética aplicada a essas vias viabiliza seu estudo isolado (Cruikshank et al., 2010).

Kravitz et al. (2010) estudaram estimulações direta e indireta das células espinhosas médias dos gânglios basais (estriato) de ratos com Parkinson e com alteração transgênica dos receptores de dopamina D1 e D2. Realizaram a expressão viral de ChR2 nos receptores e utilizaram um laser com comprimento de onda de $473 \mathrm{~nm}$ e $1 \mathrm{~mW}$ de potência. Durante a

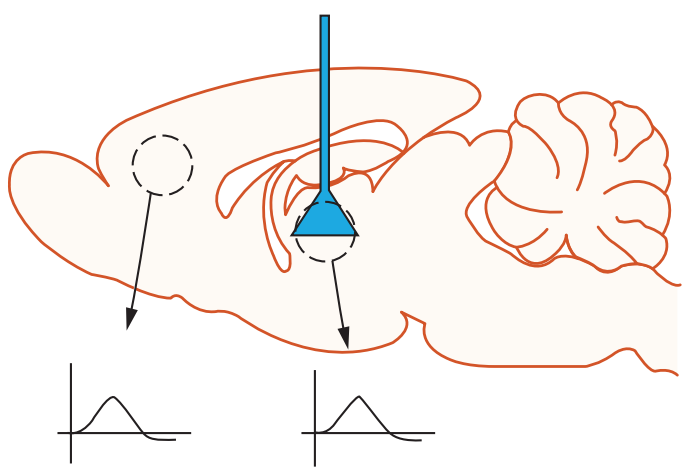

Figura 5. Estimulação óptica de células codificadas do tálamo de ratos com resposta do córtex motor primário [adaptado de Palmer (2010)] Figure 5. Optical Stimulation of cells encoded in the thalamus of rats with the primary motor cortex response [adapted from Palmer (2010)].

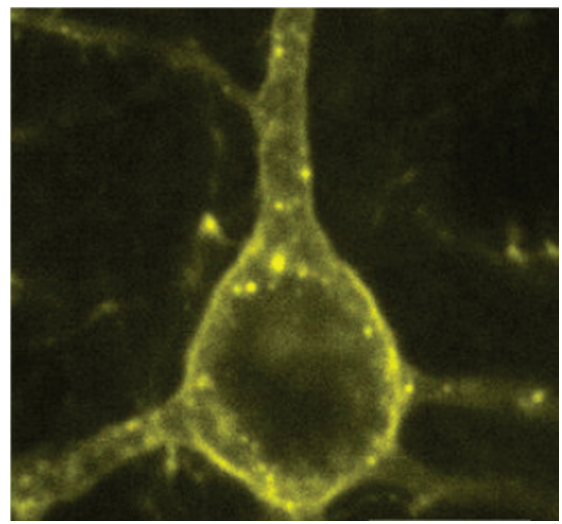

Figura 6. Neurônios piramidais de rato com modificação genética para responder a uma sinapse com a cor amarela [adaptado de Mutoh et al. (2010)].

Figure 6. Pyramidal neurons of rats with genetic modification to respond to a synapse with the yellow [adapted from Mutoh et al. (2010)]. 


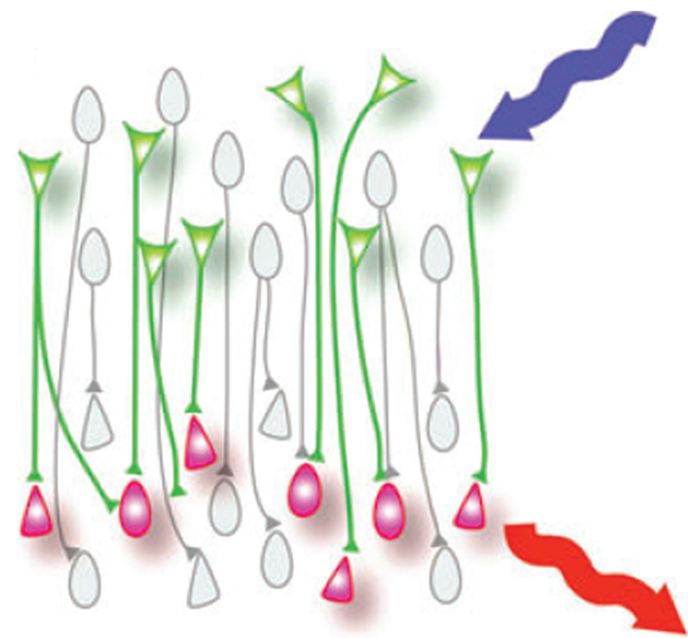

Figura 7. Neurônios codificados com optogenética e proteínas fluorescentes sensíveis à tensão elétrica [adaptado de Mancuso et al. (2011)].

Figure 7. Neurons encoded by optogenetics and voltage-sensitive fluorescent proteins [Adapted from Mancuso et al. (2011)].

estimulação óptica, os receptores de dopamina tipo D1 sofreram aumento da frequência de despolarização, de 0,03 para $1,16 \mathrm{~Hz}$. Já os receptores D2 sofreram incremento na frequência, de 0,06 para $0,76 \mathrm{~Hz}$. Os resultados mostraram que a excitação bilateral das vias indiretas das células espinhosas médias gera bradicinesia e paralisação. Do contrário, a estimulação em vias diretas da célula espinhosa média, reduz a paralisação e aumenta a locomoção.

A ativação das vias dopaminérgicas D1 e D2 que formam projeções presentes no núcleo accumbens (localizado no lobo frontal), centro de recompensa durante o uso de cocaína, ainda são superficialmente conhecidos. Lobo et al. (2010) avaliaram o efeito a estimulação óptica e optogenética com codificação dos receptores dopaminérgicos D1 e D2 sobre a ausência do TrkB (receptor do brain-derived neurotrophic factor). Utilizou-se um feixe de luz azul ( $\lambda$ igual a $473 \mathrm{~nm}$ ) com frequências de $1,1,4$ e $10 \mathrm{~Hz}$ e pulsos com duração de $200 \mathrm{~ms}$ e $1 \mathrm{~s}$. Os resultados mostraram que a ativação do receptor D2 suprimiu o sistema de recompensa da cocaína e efeitos contrários foram encontrados com a ativação do receptor D1.

Arrenberg et al. (2010) testaram a viabilidade de um marca-passo cardíaco por meio de controle optogenético. Realizaram alteração gênica de NpHR e ChR2 em células do miocárdio de peixes zebras. Os pesquisadores conseguiram simular: (1) taquicardia, (2) bradicardia, (3) bloqueio atrioventricular e parada cardíaca, tornando promissora a futura aplicação de optogenética em marca-passo cardíaco.
O locus coeruleos é uma estrutura noradrenérgica localizada no tronco cerebral com função de coordenar os estados de vigília e alerta (Saper et al., 2005). Carter et al. (2010) avaliaram, por meio de optogenética, a resposta do locus coeruleos de ratos ao estímulo óptico. Os neurônios do locus coeruleos foram modificados com o (I) ChR2 (excitatório) que responde à cor azul, e (II) NpHR, que é uma bomba de cloreto (inibitório), sensível a cor amarela. Foram utilizados dois lasers para o experimento: um (I) laser de cor azul (comprimento de onda igual a $473 \mathrm{~nm}$ ) com $20 \mathrm{~mW}$ potência, com função estimulatória e um (II) laser de cor amarela (593 nm) com efeito inibitório (hiperpolarização dos neurônios). Foram utilizadas as técnicas de medição de eletroencefalografia (EEG) e eletromiografia (EMG) da musculatura do pescoço. A fotoinibição do locus coeruleos causa a redução da duração de vigília. A fotoestimulação do locus coeruleos causa mudança do estado de sono para vigília, imediatamente após a estimulação no período de sono não REM, e alguns segundos após o início da estimulação no estágio de sono REM. Os resultados mostraram que com $1 \mathrm{~h}$ de aplicação contínua, o laser azul (estimulatório) aumentava-se a duração do período de vigília. Entretanto, frequências acima de $5 \mathrm{~Hz}$ causaram estado de paralisação temporária do movimento, assemelhando-se à cataplexia, registrado pela EMG, que cessava apenas 15-20 s após a interrupção do estímulo (Carter et al., 2010).

O deslocamento do globo ocular com o objetivo de redirecionar a fixação visual de um objeto qualquer é denominado de sacada (Costa, 2007). Por meio da optogenética, Schoonheim et al. (2010) conseguiram localizar o centro neural do movimento de sacada no tronco cerebral de larvas de peixe zebra (Danio Rerio). Recentemente, Leifer et al. (2011) estudaram o circuito motor e mecano-sensorial de vermes (Caenorhabditis elegans) também com técnicas da optogenética. Foram utilizados os canais ChR2 (estimulatório) e NpHR (inibitório) com comprimentos de onda ( $\lambda$ ) de $473 \mathrm{~nm}$ (azul) e $532 \mathrm{~nm}$ (amarelo), respectivamente. Goold e Nicoll (2010), aplicaram optogenética a cultura de neurônios piramidais de ratos envolvidos na formação da memória da área CA1 do hipocampo. Os canais codificados foram os receptores do neurotransmissor glutamato AMPA e NMDA. Foi utilizado diodo operando com um comprimento de onda igual a $470 \mathrm{~nm}$ e uma potência de $195 \mathrm{~mW}$, aplicada em uma área de $1.963 \mathrm{~mm}^{2}$, onde o estudo mostrou a viabilidade do uso em neurônios piramidais.

Paralikar et al. (2010) desenvolveram um protótipo de estimulador óptico para optogenética implantável, com configurações ajustáveis no comprimento de onda em $473 \mathrm{~nm}$ e $535 \mathrm{~nm}$, ativador do ChR2 e inibidor do 
$\mathrm{NpHR}$, respectivamente. A densidade de potência de saída pode ser regulada em até $5,3 \mathrm{~mW} / \mathrm{cm}^{2}$, para cada um dos dois canais independentemente. A frequência pode ser ajustada entre 0,153 e $200 \mathrm{~Hz}$, e a duração do pulso ajustada de $100 \mu$ s à períodos acima de $10 \mathrm{~ms}$. Im et al. (2011) projetaram e desenvolveram uma sonda neural com aplicação em optogenética como mostra a Figura 8. Possibilitando estimulação com luz azul e amarela, com potência de saída de até $50 \mu \mathrm{W}$, intensidade suficiente para despolarizar/ inibir regiões neurais codificadas com optogenética.

Iwai et al. (2011) desenvolveram um dispositivo de baixo custo, pequeno, acionado por LED para estimulação óptica dos neurônios corticais de ratos e proporciona movimentação livre por ser controlado com tecnologia sem fio. O dispositivo é facilmente montado sobre a cabeça de um rato com um bloco de polímero e opera com uma tensão de $5 \mathrm{~V}-6 \mathrm{~V}$. Zhang et al. (2009), como mostra a Figura 9, desenvolveram uma matriz de cem elementos, onde um era a sonda óptica e os outros eletrodos de medição eletrofisiológica, com a capacidade de aplicar a estimulação óptica e gravar os sinais neurais sem gerar interferência no sinal captado, o que ocorre quando o estímulo utilizado é elétrico.

\section{Estimulação óptica neural}

A utilização de laser na faixa do infravermelho de baixa intensidade (Wells et al., 2005) sobre o tecido neural com o objetivo de deflagrar potenciais de ação denomina-se estimulação neural por infravermelho, do inglês infrared neural stimulation (Cayce et al., 2010b). Ao contrário da estimulação elétrica funcional, a estimulação neural por infravermelho não necessita do contato direto de eletrodos com o tecido e é muito seletiva a feixes nervosos dentro do nervo (Duke et al., 2009; Izzo et al., 2006b).

O estimulador neural por infravermelho comercial com aplicações não humanas Capella (modelo R 1850), da marca Aculight ${ }^{\circledR}$, como mostra a Figura 10, apresenta uma profundidade de aplicação de 300 a $600 \mu \mathrm{m}$, necessitando que sua sonda esteja muito próxima ou adjacente ao tecido nervoso (Aculight, 2010). A estimulação óptica aplicada a $300 \mu \mathrm{m}$ do modíolo (estrutura óssea da cóclea) reduz em aproximadamente $68 \%$ a amplitude dos potenciais de ação compostos do nervo auditivo comparado quando ele está totalmente em contato (Izzo et al., 2006b). Em ratos com o nervo ciático exposto, a estimulação é realizada a aproximadamente $700 \mu \mathrm{m}$ da superfície do nervo (Duke et al., 2009). A Tabela 3 mostra os parâmetros utilizados nesse tipo de aplicação entre os anos de 2006 a 2010.

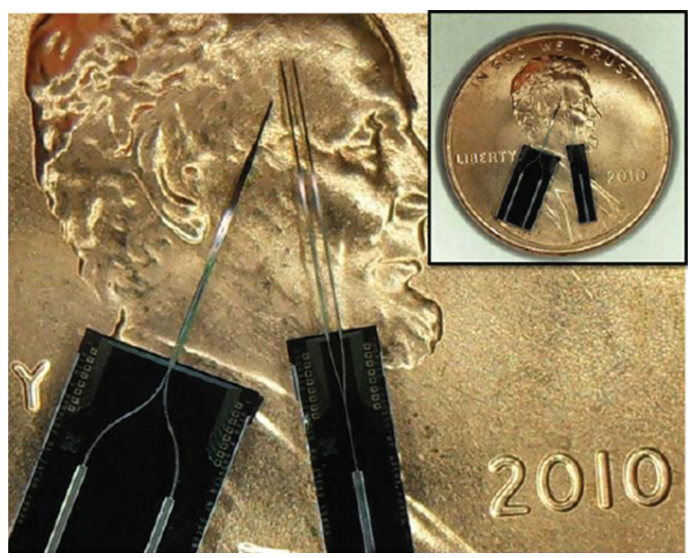

Figura 8. Sonda neural com aplicação em optogenética [adaptado de Im et al. (2011)].

Figure 8. Neural probe for applications in optogenetics [adapted from Im et al. (2011)].

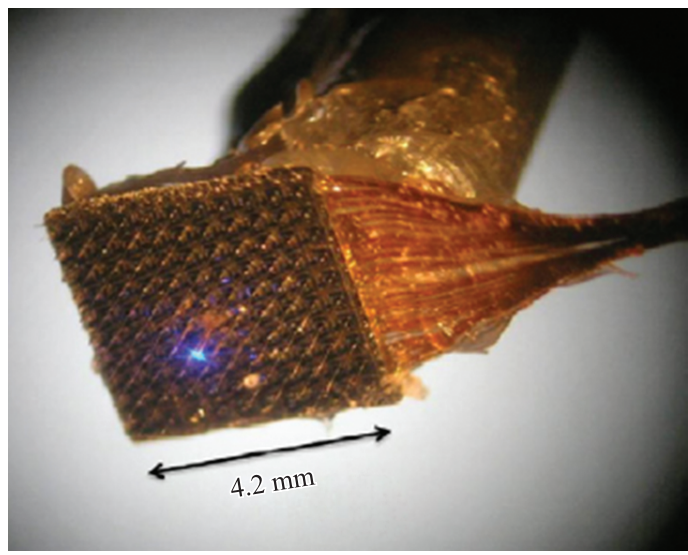

Figura 9. Matriz de cem elementos para estimulação óptica e aquisição de sinal eletrofisiológico encefálico [adaptado de Zhang et al. (2009)]. Figure 9. Matrix of one hundred optical stimulation elements and electrophysiological brain signal acquisition [adapted from Zhang et al. (2009)].

Da mesma forma que na estimulação elétrica, na $E O$, quanto maior a frequência, menor a amplitude necessária para despolarizar um neurônio (Cayce et al., 2010b). Wells et al. (2007b) estudaram a aplicação de EO com laser de $\mathrm{YAG}\left(\mathrm{Y}_{3} \mathrm{Al}_{5} \mathrm{O}_{12}\right)$ em nervos periféricos com testes histológicos para avaliarem as alterações ocorridas. Segundo Wells et al. (2007b), a frequência de pulsos desse laser para estimulação segura está limitada em aproximadamente $5 \mathrm{~Hz}$. Nessa faixa não foram observadas lesões tissulares em nervos periféricos (nervos femorais, fibulares e tibiais de ratos) como flictenas (bolhas) e edema. Além disso, radiações de EO entre $0,66-0,70 \mathrm{~J} / \mathrm{cm}^{2}$ apresentam probabilidade menor que $1 \%$ de ocasionarem danos térmicos (Wells et al., 2007b) já em intensidades acima de $50 \mathrm{~J} / \mathrm{cm}^{2}$ 
causam desidratação do tecido nervoso (Wells et al., 2007a). Ainda conforme Wells et al. (2007a), para comprimentos de onda $(\lambda)$ entre 2,1 a $1,87 \mu \mathrm{m}$ (infra-vermelho), o limiar de despolarização da célula nervosa $\left(0,3-0,4 \mathrm{~J} / \mathrm{cm}^{2}\right)$ é aproximadamente
2,5 vezes menor que a intensidade lesiva ao tecido $\left(0,8-1,0 \mathrm{~J} / \mathrm{cm}^{2}\right)$.

Uma das vantagens da EO é a garantia de seletividade das estruturas estimuladas, como quando aplicada sobre o nervo auditivo em

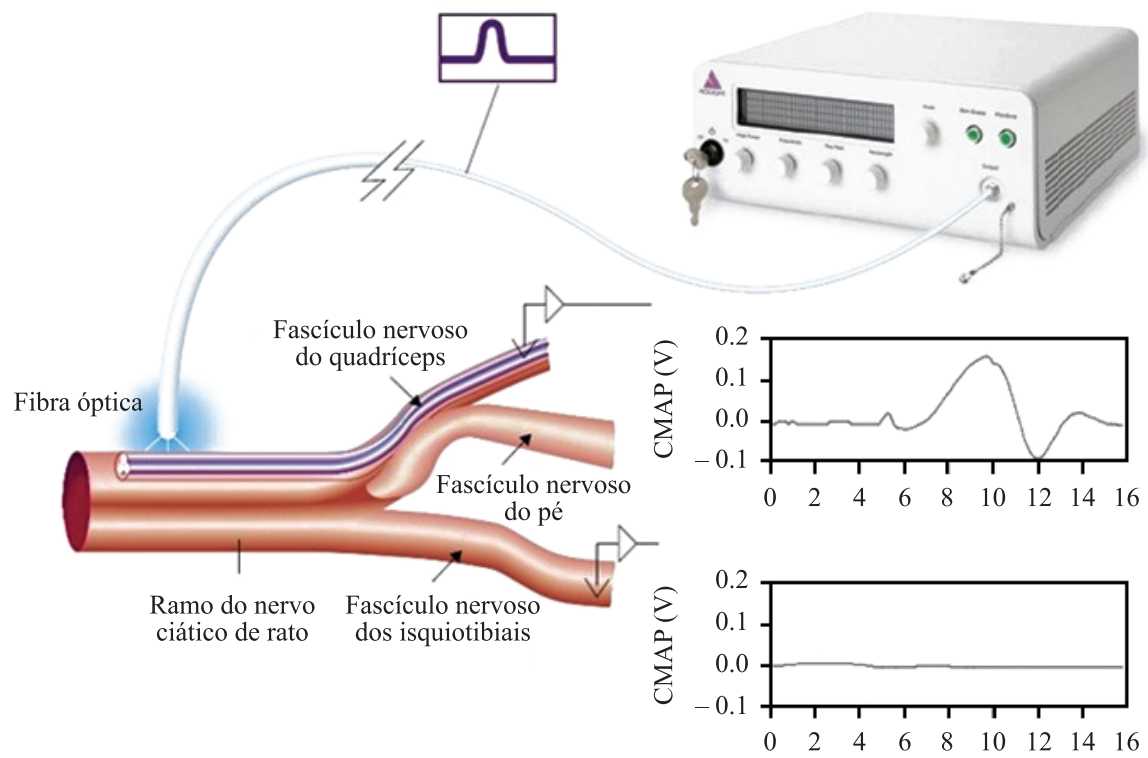

Figura 10. Estimulador neural por infravermelho comercial Capella (modelo R 1850), da marca Aculight ${ }^{\circledR}$, e sua aplicação seletiva sobre feixes nervosos [adaptado de Aculight (2010)].

Figure 10. Neural stimulator for commercial infrared Capella (model $R$ 1850), Aculight ${ }^{\circledR}$ brand, and its selective application on nerve bundles [adapted from Aculight (2010)].

Tabela 3. Parâmetros utilizados para estimulação óptica por infra-vermelho entre os anos de 2006 a 2010.

Table 3. Stimulation parameters used for optical infra-red between the years 2006 to 2010.

\begin{tabular}{|c|c|c|c|c|c|c|}
\hline Autor & $\begin{array}{c}\lambda \\
(\mu m)\end{array}$ & $\begin{array}{c}\tau \\
(\mu s)\end{array}$ & $\begin{array}{l}\text { Frequência } \\
\quad(\mathrm{Hz})\end{array}$ & $\begin{array}{l}\text { Diâmetro da } \\
\text { fibra óptica } \\
\qquad(\mu \mathrm{m})\end{array}$ & $\begin{array}{l}\text { Radiação } \\
\left(\mathrm{J} / \mathrm{cm}^{2}\right)\end{array}$ & Aplicado em \\
\hline Izzo et al. (2006b) & 2,12 & 250 & 2 & 100 & $0,01-0,1$ & Nervo auditivo de rato \\
\hline Izzo et al. (2006a) & 2,12 & 250 & 2 & 100 & $0,01-0,06$ & Implante coclear de rato \\
\hline Wells et al. (2007b) & 2,12 & 350 & $2-8$ & 600 & $0,2-1,5$ & Nervo ciático de rato \\
\hline Izzo et al. (2007) & $1,84-1,88$ & $35-1000$ & $1-13$ & 200 & $0,001-0,1$ & $\begin{array}{l}\text { Estimulação do sistema } \\
\text { auditivo de rato }\end{array}$ \\
\hline Teudt et al. (2007) & 2,12 & 250 & 2 & 600 & $0,71-2,2$ & Nervo facial de rato \\
\hline Fried et al. (2007) & 1,87 & 2500 & 10 & 300 & 1 & Nervo cavernoso de rato \\
\hline Wells et al. (2007a) & $\begin{array}{l}2,12 \\
2-10 \\
0,75 \\
1,87\end{array}$ & $\begin{array}{c}350 \\
5 \\
350 \\
10^{3}-10^{4}\end{array}$ & $2-10$ & 600 & $0,3-51,7$ & Nervo ciático de rato \\
\hline Richter et al. (2008) & $1,84-1,87$ & $\begin{array}{l}30 ; 60 ; 100 ; \\
200 ; 400 ; 800 \\
\quad \text { e } 1600\end{array}$ & 13 & 200 & $0,003-0,9$ & Nervo auditivo de rato \\
\hline Harris et al. (2009)§ & $1,82-1,84$ & 10-contínuo & $*$ & 300 & * & $\begin{array}{l}\text { Implante vestibular em } \\
\text { suíno }\end{array}$ \\
\hline Wininger et al. (2009) & 1,85 & $200-2000$ & $\mathrm{PU}$ & 600 & $0,1-1$ & Nervo da pata de lagosta \\
\hline Duke et al. (2009) & 1,87 & $*$ & 2 & 400 & $1,69 \pm 0,30$ & Nervo ciático de rato \\
\hline Cayce et al. (2010a) & $1,87-1,94$ & 250 & $10-200$ & 400 & $0,01-0,5$ & $\begin{array}{l}\text { Córtex somatossensorial } \\
\text { de rato }\end{array}$ \\
\hline
\end{tabular}

$\lambda$ : comprimento de onda; $\tau$ : duração do pulso; PU: pulso único; $\S$ : estimulador óptico por comprimentos de onda que respondem aos canais iônicos codificados por infravermelho comercial Capella R-1850 (Aculight ${ }^{\circledR}$ ).

$\lambda$ : wavelength, $\tau$ : pulse duration; PU: single pulse; $\S$ : stimulator optical infra-red commercial Capella R-1850 (Aculight $\left.{ }^{\circledR}\right)$. 
implantes cocleares (Izzo et al., 2006b), além do uso para futuros implantes visuais (Kim et al., 2004). Richter et al. (2008) aplicaram EO sobre feixes do nervo auditivo em surdez aguda e crônica de ratos Gerbil (Meriones unguiculatus). Os resultados foram positivos em ambos os estágios de surdez; entretanto, o limiar de despolarização foi maior na surdez crônica, necessitando de uma intensidade maior para gerar um potencial evocado. Izzo et al. (2006b) mostraram que a EO pode ativar o nervo auditivo de ratos adultos com respostas em 20 a $40 \mathrm{~dB}$ sem ocasionar dano tecidual ao nervo auditivo.

Izzo et al. (2007) utilizaram laser de diodo sobre o sistema auditivo (central) de ratos Gerbil (Meriones unguiculatus) para avaliar os potenciais de ação evocados pela EO. O laser foi fixado a aproximadamente $0,5 \mathrm{~mm}$ das células do gânglio espiral. Os resultados mostraram que os parâmetros de duração de pulso de $35 \mu$ s a uma frequência de $13 \mathrm{~Hz}$ mantinham a despolarização das células constante $\mathrm{e}$ estável. Esses resultados indicam que um laser pulsado com uma frequência acima de $10 \mathrm{~Hz}$ é favorável para a EO, diferenciando-se dos resultados de Wells et al. (2007b), que afirmam que uma frequência segura seria aproximadamente $5 \mathrm{~Hz}$. Izzo et al. (2007) estudaram também a relação entre o comprimento de onda $(\lambda)$ e a penetração óptica mantendo os demais parâmetros fixos. Os resultados demonstraram que a penetração óptica partiu de $308 \mu \mathrm{m}$ para um $(\lambda)$ de 1,88 , para $1.129 \mu \mathrm{m}$ para um $(\lambda)$ de 1,84 , evidenciando que quanto menor o comprimento de onda, maior a penetração do laser no tecido.

A estimulação elétrica é considerada como padrão ouro para ativação artificial do sistema nervoso central (Azoulay-Zyss et al., 2011) e periférico (Yu e Chang, 2010), mas pode estimular estruturas adjacentes resultando em artefatos indesejados. A estimulação neural por infravermelho pode ser aplicada ao sistema nervoso central sem gerar artefatos por ser pontual (Cayce et al., 2010b). Além disso, podemos citar o uso de tecnologia óptica para aquisição de imagem (como Yanai et al. (2005), que desenvolveram uma tomografia óptica com diodos laser de emissão para $\lambda$ iguais a $780 \mathrm{~nm}$ e $830 \mathrm{~nm}$ ) e recepção, para medir a variação de oxigênio na região cerebral.

Dentre as aplicações viáveis para a EO encontra-se a estimulação encefálica profunda (Cayce et al., 2010b). Cayce et al. (2010a) aplicaram no córtex somatossensorial (região do lobo parietal) de ratos, trens de pulsos durante $500 \mathrm{~ms}$ com um tempo inativo de 15 a $30 \mathrm{~s}$. Comparou-se o estímulo óptico aplicado ao córtex com o estímulo mecânico (piezoelétrico) a $8 \mathrm{~Hz}$ aplicado à pata do animal com registro eletrofisiológico. Uma coleta de imagem por microscopia cirúrgica do córtex cerebral mostrou que a EO não gerou dano ao tecido encefálico. Os resultados mostraram que a estimulação neural por infravermelho no córtex somotassensorial causou um efeito inibitório, levando-os a concluir que implantes neurais por meio de estimulação neural por infravermelho podem ser viáveis para a concepção de próteses neurais para controle em malha fechada.

Wininger et al. (2009) estudaram em nervos ex vivo de patas de lagosta (Homarus americanus) a EO e elétrica, com registro elétrico e óptico. Utilizaram estimulação elétrica pulsada com duração de 0,2 ms em intervalos de 1-2 s, corrente de $10 \mu \mathrm{A}$ a $2 \mathrm{~mA}$ e tensão de $3 \mathrm{~V}$ a $30 \mathrm{~V}$. A EO (sonda) ficou posicionada a aproximadamente $0,75 \mathrm{~mm}$ da inervação. Um LED com emissão em $665 \mathrm{~nm}$ irradiava os feixes nervosos, enquanto um fotodiodo e polarizadores cruzados posicionados adjacentes ao tecido captavam a variação de birrefringência do LED durante a estimulação nervosa. Os resultados mostraram que foi possível reconhecer o potencial de ação por meio da birrefringência, mas que a resposta teve um atraso maior que do sinal eletrofisiológico. O sinal óptico mostrou menor interferência que o elétrico no sinal eletrofisiológico. Para Wininger et al. (2009), a combinação de EO com a gravação óptica vem a ser uma promissora ferramenta na engenharia neural, tornando futuramente desnecessário o uso de fios hoje utilizados durante gravações eletrofisiológicas.

A aplicação de EO amplia-se da utilização para implante coclear (Izzo et al., 2006a) para o uso no sistema vestibular responsável pelo equilíbrio e funções proprioceptivas (Bear et al., 2002). Como nas pesquisas de Harris et al. (2009), que ativaram o ramo vestibular do oitavo par craniano por meio de estimulação neural por infra-vermelho e compararam com a ativação por estimulação elétrica. $\mathrm{O}$ posicionamento dos eletrodos e do laser de diodo foi na região da ampola dos canais do labirinto. A estimulação elétrica foi bifásica com um conversor tensão-corrente entre 160 - $710 \mu \mathrm{A}$, para uma frequência de $100 \mathrm{~Hz}$. A EO teve sua calibração com um pico de potência que fornecia até $1,26 \mathrm{~W}$. As ativações ópticas e elétricas deveriam proporcionar movimentos oculares com registros. Os resultados foram negativos para a $\mathrm{EO}$, na qual não se obteve os mesmos efeitos fisiológicos (movimentos oculares evocados) que com estimulação elétrica.

Alternativamente à aplicação de EO por infra-vermelho no tecido neural, Kötter et al. (2005) utilizaram EO na faixa de ultra-violeta nos neurônios piramidais da $\mathrm{V}$ camada do córtex de ratos para liberação do neurotransmissor glutamato enjaulado. A experiência consistia em aplicar luz de xenon sobre 
uma estrutura química com o ácido L-glutâmico e $\gamma$-[a-carboxi-2-nitrobenzil]-ester que após a aplicação óptica, liberava um grupo carboxi-nitrobenzil e o neurotransmissor glutamato. A ativação do flash de xenon pode influenciar na liberação de glutamato em até $200 \mu \mathrm{m}$ do ponto de ativação, tornando o uso de ultra-violeta uma perspectiva para outros fármacos no tecido encefálico.

Teudt et al. (2007) utilizaram a estimulação por infra-vermelho no nervo facial de ratos Gerbil (Meriones unguiculatus). Foi medida a ativação dos músculos faciais: orbicular do olho, levantador do lábio superior e da asa do nariz e o músculo orbicular da boca e analisado o nível de lesão tissular causada pelo laser sobre o nervo facial e seus ramos. Histologicamente, comprovou-se danos aos feixes nervosos com uma radiação de $2,2 \mathrm{~J} / \mathrm{cm}^{2}$, mas não ficou comprovada lesão aparente em uma intensidade de $2,0 \mathrm{~J} / \mathrm{cm}^{2}$. Esses resultados viabilizam a EO para ativar seletivamente ramos do nervo fácil, principalmente em processo cirúrgico com o objetivo de poupar estruturas sadias da extirpação. Com o mesmo escopo de utilizar a estimulação neural por infravermelho para poupar estruturas sadias, Fried et al. (2007) fizeram uso da EO do nervo cavernoso durante cirurgia de câncer de próstata para preservar a condição sexual após a cirurgia.

\section{Conclusão}

A aplicação de estímulos ópticos no campo da biomedicina vem crescendo gradativamente. A estimulação neural óptica e a optogenética despontam positivamente, tanto como ferramenta de pesquisa como em aplicações clínicas.

A estimulação neural por infravermelho não necessita contato direto com o tecido, o que lhe confere uma grande vantagem em relação à estimulação elétrica, mas tem efetividade restrita ao evocar resposta nos neurônios (ativação-despolarização). Por outro lado, a seletividade do estímulo óptico é superior ao estímulo elétrico, tornando o estímulo óptico mais indicado para implantes do sistema nervoso (coclear, vestibular).

A optogenética pode ser utilizada para manipular o tecido neural despolarizando ou hiperpolarizando os neurônios codificados, além de monitorar as ativações por meio de codificação de proteínas fluorescentes sensíveis à tensão elétrica. Isso permite rastrear estímulos viabilizando a identificação de circuitos intra-cerebrais de um modo não invasivo. Além disso, é possível mapear os circuitos alterados, sendo de grande valia em avaliações e aplicações neuro-psicológicas.
A estimulação óptica por infravermelho e a optogenética são dois campos de pesquisa novos, mas em expansão, cujas pesquisas vem sendo aplicadas apenas a modelos animais. Entretanto, os resultados apresentados nos trabalhos relacionados a tais temas mostram um horizonte promissor de aplicações em seres humanos, podendo até mesmo vir a substituir métodos considerados padrão ouro (estimulação elétrica) na ativação e pesquisa de circuitos neurais.

\section{Agradecimentos}

Os autores agradecem à CAPES e ao CNPq pelas bolsas concedidas para a realização deste trabalho.

\section{Referências}

Aculight. Aculight Laser Solutions. Capella. Bothell, WA, USA. [cited 2010 Dec 21]. Available from: www.aculight. com/Downloads/CapellaDatasheet.pdf

Andrasfalvy BK, Zemelman BV, Tang J, Vaziri A. Two-photon single-cell optogenetic control of neuronal activity by sculpted light. Proceedings of the National Academy of Sciences; 2010. p. 11981-6. http://dx.doi.org/10.1073/ pnas. 1006620107

Arrenberg AB, Stainier DYR, Baier H, Huisken J. Optogenetic control of cardiac function. Science. 2010; 330(6006):971-4. http://dx.doi.org/10.1126/science.1195929

Azoulay-Zyss J, Roze E, Welter ML, Navarro S, Yelnik J, Clot F, Bardinet E, Karachi C, Dormont D, Galanaud D. Bilateral deep brain stimulation of the pallidum for myoclonus-dystonia due to \{varepsilon\}-sarcoglycan mutations: A pilot study. Archives of Neurology. 2011; 68(1):94-8.

Baylor D. How photons start vision. Proceedings of the National Academy of Sciences of the United States of America. 1996; 93(2):560-5. http://dx.doi.org/10.1073/ pnas. 93.2 .560

Bean BP. The action potential in mammalian central neurons. Nature Reviews Neuroscience. 2007; 8(6):451-65.http:// dx.doi.org/10.1038/nrn2148

Bear MF, Connors BW, Paradiso MA. Neurociências: Desvendando o sistema nervoso. 2. ed. Porto Alegre: Artmed; 2002.

Carter ME, Yizhar O, Chikahisa S, Nguyen H, Adamantidis A, Nishino S, Deisseroth K, De Lecea L. Tuning arousal with optogenetic modulation of locus coeruleus neurons. Nature Neuroscience. 2010; 13(12):1526-33. http://dx.doi. org/10.1038/nn.2682

Cayce JM, Friedman R, Roe AW, Konrad PE, Jansen ED, Mahadevan-Jansen A. Relating optical signals induced by infrared neural stimulation to electrophysiology. In: BSEC: Proceedings of Biomedical Sciences and Engineering Conference-; 2010 May 25-26; Oak Ridge. Oak Ridge; 2010a. p. 1-4. http://dx.doi.org/10.1109/BSEC.2010.5510836 
Cayce JM, Kao CC, Malphrus JD, Konrad PE, MahadevanJansen A, Jansen ED. Infrared neural stimulation of thalamocortical brain slices. IEEE Journal of Selected Topics in Quantum Electronics. 2010b; 16(3):565-72. http:// dx.doi.org/10.1109/JSTQE.2009.2032424

Costa MF. Movimentos oculares no bebê: o que eles nos indicam sobre o status oftalmológico e neurológico. Psicologia USP. 2007; 18(2):47-61.

Cruikshank SJ, Urabe H, Nurmikko AV, Connors BW. Pathway-specific feedforward circuits between thalamus and neocortex revealed by selective optical stimulation of axons. Neuron. 2010; 65(2):230-45. http://dx.doi.org/10.1016/j. neuron.2009.12.025

Deisseroth K, Feng G, Majewska AK, Miesenbock G, Ting A, Schnitzer MJ. Next-generation optical technologies for illuminating genetically targeted brain circuits. Journal of Neuroscience. 2006; 26(41):10380-6. http://dx.doi. org/10.1523/JNEUROSCI.3863-06.2006

Duke AR, Cayce JM, Malphrus JD, Konrad P, MahadevanJansen A, Jansen ED. Combined optical and electrical stimulation of neural tissue in vivo. Journal of Biomedical Optics. 2009; 14(6):1-3. http://dx.doi.org/10.1117/1.3257230

Fiala A, Suska A, Schlüter OM. Optogenetic approaches in neuroscience. Current Biology. 2010; 20(20):R897-903. http://dx.doi.org/10.1016/j.cub.2010.08.053

Figueiredo M, Lane S, Tang F, Liu BH, Hewinson J, Marina N, Kasymov V, Souslova EA, Chudakov DM, Gourine AV. Optogenetic experimentation on astrocytes. Experimental Physiology. 2011; 96(1):40-50. http://dx.doi.org/10.1113/ expphysiol.2010.052597

Fried NM, Rais-Bahrami S, Lagoda GA, Chuang A, Su L, Burnett AL. Identification and imaging of the nerves responsible for erectile function in rat prostate, in vivo, using optical nerve stimulation and optical coherence tomography. IEEE Journal of Selected Topics in Quantum Electronics. 2007; 13(6):1641-5. http://dx.doi.org/10.1109/ JSTQE.2007.910119

Goold CP, Nicoll RA. Single-cell optogenetic excitation drives homeostatic synaptic depression. Neuron. 2010; 68(3):51228. http://dx.doi.org/10.1016/j.neuron.2010.09.020

Gradinaru V, Zhang F, Ramakrishnan C, Mattis J, Prakash R, Diester I, Goshen I, Thompson KR, Deisseroth K. Molecular and cellular approaches for diversifying and extending optogenetics. Cell. 2010; 141(1):154-65. http:// dx.doi.org/10.1016/j.cell.2010.02.037

Gunaydin LA, Yizhar O, Berndt A, Sohal VS, Deisseroth K, Hegemann P. Ultrafast optogenetic control. Nature Neuroscience. 2010; 13(3):387-92. http://dx.doi.org/10.1038/ nn. 2495

Haines DE. Neuroanatomy: An atlas of structures sections, and systems. 7th ed. Lippincott Williams \& Wilkins; 2008.

Harris DM, Bierer SM, Wells JD, Phillips JO. Optical nerve stimulation for a vestibular prosthesis. In: SPIE Conference: Proceedings of SPIE; 2009; San Jose, California. San Jose; 2009. v. 7180, p. 1-4. http://dx.doi. org/10.1117/12.810197
Hegemann P, Möglich A. Channelrhodopsin engineering and exploration of new optogenetic tools. Nature Methods. 2010; 8(1):39-42. http://dx.doi.org/10.1038/ nmeth.f.327

Hubbell WL, Bownds MD. Visual transduction in vertebrate photoreceptors. Annual Review of Neuroscience. 1979; 2(1):17-34. http://dx.doi.org/10.1146/ annurev.ne.02.030179.000313

Im M, Cho IJ, Wu F, Wise KD, Yoon E. Neural probes integrated with optical mixer/splitter waveguides and multiple stimulation sites. In: IEEE International Conference on Micro Electro Mechanical Systems: Proceedings of 24th IEEE International Conference on Micro Electro Mechanical Systems; 2011 Jan 23-27; Cancum, Mexico. IEEE; 2011. p. 1051-4. http://dx.doi.org/10.1109/MEMSYS.2011.5734609

Iwai Y, Honda S, Ozeki H, Hashimoto M, Hirase H. A simple head-mountable LED device for chronic stimulation of optogenetic molecules in freely moving mice. Neuroscience Research. 2011; 70(1):124-7. http://dx.doi.org/10.1016/j. neures.2011.01.007

Izzo A, Pathria J, Suh E, Whitlonb D, Jansen E, Richter C. Selectivity of optical stimulation in the auditory system. Proceedings of SPIE. 2006A; 6078(2006):60781P-1-8. http://dx.doi.org/10.1117/12.659743

Izzo AD, Richter CP, Jansen ED, Walsh Junior JT. Laser stimulation of the auditory nerve. Lasers in Surgery and Medicine. 2006B; 38(8):745-53. http://dx.doi.org/10.1002/ $1 \mathrm{sm} .20358$

Izzo AD, Walsh JT, Jansen ED, Bendett M, Webb J, Ralph $\mathrm{H}$, Richter CP. Optical parameter variability in laser nerve stimulation: a study of pulse duration, repetition rate, and wavelength. IEEE Transactions on Biomedical Engineering. 2007; 54(6):1108-14. http://dx.doi.org/10.1109/ TBME.2007.892925

Kim ET, Seo JM, Zhou JA, Jung H, Kirn SJ. A retinal implant technology based on flexible polymer electrode and optical/electrical stimulation. In: IEEE International Workshop on Biomedical Circuits \& Systems: Proceedings of IEEE International Workshop on Biomedical Circuits \& Systems; 2004; Singapore. IEEE; 2004. p. 12-5.

Kötter R, Schubert D, Dyhrfjeld-Johnsen J, Luhmann HJ, Staiger JF. Optical release of caged glutamate for stimulation of neurons in the in vitro slice preparation. Journal of Biomedical Optics. 2005; 10(1):011003-1-15. http://dx.doi. org/10.1016/j.jneumeth.2004.07.004

Kraft TW, Schneeweis DM, Schnapf JL. Visual transduction in human rod photoreceptors. Journal of Physiology. 1993; 464(1):747-65.

Kravitz AV, Freeze BS, Parker PRL, Kay K, Thwin MT, Deisseroth K, Kreitzer AC. Regulation of parkinsonian motor behaviours by optogenetic control of basal ganglia circuitry. Nature. 2010; 466(7306):622-6. http://dx.doi. org/10.1038/nature09159

Lee JH, Durand R, Gradinaru V, Zhang F, Goshen I, Kim DS, Fenno LE, Ramakrishnan C, Deisseroth K. Global and local fMRI signals driven by neurons defined optogenetically 
by type and wiring. Nature. 2010; 465(7299):788-92. http:// dx.doi.org/10.1038/nature09108

Leifer AM, Fang-Yen C, Gershow M, Alkema MJ, Samuel ADT. Optogenetic manipulation of neural activity in freely moving Caenorhabditis elegans. Nature Methods. 2011; 8(2):147-52. http://dx.doi.org/10.1038/nmeth.1554

Ling YM, Wu SE. $350 \mathrm{~mW}$ high-power He-Ne laser and its application in photodynamic therapy. Review of Scientific Instruments. 2005; 76:126107-1. http://dx.doi. org/10.1063/1.2148988

Liu X, Tonegawa S. Optogenetics 3.0. Cell. 2010; 141(1):22-4. http://dx.doi.org/10.1016/j.cell.2010.03.019

Lobo MK, Covington HE, Chaudhury D, Friedman AK, Sun HS, Damez-Werno D, Dietz DM, Zaman S, Koo JW, Kennedy PJ. Cell type-specific loss of BDNF signaling mimics optogenetic control of cocaine reward. Science. 2010; 330(6002):385-90. http://dx.doi.org/10.1126/ science. 1188472

Machado ABM. Neuroanatomia funcional. 2a ed. São Paulo: Atheneu; 2006.

Mancuso JJ, Kim J, Lee S, Tsuda S, Chow NBH, Augustine GJ. Optogenetic probing of functional brain circuitry. Experimental Physiology. 2011; 96(1):26-33.

Möglich A, Moffat K. Engineered photoreceptors as novel optogenetic tools. Photochemical \& Photobiological Sciences. 2010; 9(10):1286-300. http://dx.doi.org/10.1039/ c0pp00167h

Mutoh H, Perron A, Akemann W, Iwamoto Y, Knöpfel T. Optogenetic monitoring of membrane potentials. Experimental Physiology. 2010; 96:13-18. http://dx.doi. org/10.1113/expphysiol.2010.053942

Naeser MA, Hahn KAK, Lieberman BE, Branco KF. Carpal tunnel syndrome pain treated with low-level laser and microamperes transcutaneous electric nerve stimulation: a controlled study. Archives of Physical Medicine and Rehabilitation. 2002; 83(7):978-88. http://dx.doi.org/10.1053/ apmr.2002.33096

Niemz MH. Laser-tissue interactions: fundamentals and applications. 3rd ed. Berlin: New York: Springer Verlag; 2004

Palmer H. Optogenetic fMRI sheds light on the neural basis of the BOLD signal. Journal of neurophysiology. 2010; 104(4):1838-40. http://dx.doi. org/10.1152/jn.00535.2010

Paralikar K, Cong P, Santa W, Dinsmoor D, Hocken B, Munns G, Giftakis J, Denison T. An implantable $5 \mathrm{~mW} /$ channel dual-wavelength optogenetic stimulator for therapeutic neuromodulation research. In: IEEE International Solid-State Circuits Conference: Proceedings of IEEE International Solid-State Circuits Conference; 2010 Feb 7-11; San Francisco. IEEE; 2010. p. 238-9. http://dx.doi.org/10.1109/ ISSCC.2010.5433938

Richter CP, Bayon R, Izzo AD, Otting M, Suh E, Goyal S, Hotaling J, Walsh Junior JT. Optical stimulation of auditory neurons: Effects of acute and chronic deafening. Hearing research. 2008; 242(1-2):42-51. http://dx.doi.org/10.1016/j. heares.2008.01.011
Ryu MH, Moskvin OV, Siltberg-Liberles J, Gomelsky M. Natural and engineered photoactivated nucleotidyl cyclases for optogenetic applications. Journal of Biological Chemistry. 2010; 285(53):41501-8. http://dx.doi.org/10.1074/ jbc.M110.177600

Saper CB, Scammell TE, Lu J. Hypothalamic regulation of sleep and circadian rhythms. Nature. 2005; 437(7063):1257-63. http://dx.doi.org/10.1038/ nature 04284

Schoonheim PJ, Arrenberg AB, Del Bene F, Baier $\mathrm{H}$. Optogenetic localization and genetic perturbation of saccade-generating neurons in zebrafish. Journal of Neuroscience. 2010; 30(20):7111-20.http://dx.doi. org/10.1523/JNEUROSCI.5193-09.2010

Teh C, Chudakov DM, Poon KL, Mamedov IZ, Sek JY, Shidlovsky K, Lukyanov S, Korzh V. Optogenetic in vivo cell manipulation in KillerRed-expressing zebrafish transgenics. BMC Developmental Biology. 2010; 10(110):1-12. http:// dx.doi.org/10.1186/1471-213X-10-110

Teudt IU, Nevel AE, Izzo AD, Walsh Junior JT, Richter CP. Optical stimulation of the facial nerve: a new monitoring technique? The Laryngoscope. 2007; 117(9):1641-7. http:// dx.doi.org/10.1097/MLG.0b013e318074ec00

Valchinov ES, Pallikarakis NE. Design and testing of low intensity laser biostimulator. BioMedical Engineering OnLine. 2005; 4:1-10.

Wells J, Kao C, Konrad P, Milner T, Kim J, Mahadevan-Jansen A, Jansen ED. Biophysical mechanisms of transient optical stimulation of peripheral nerve. Biophysical Journal. 2007A; 93(7):2567-80. PMid:17526565 PMCid:1965456. http://dx.doi.org/10.1529/biophysj.107.104786

Wells J, Kao C, Mariappan K, Albea J, Jansen ED, Konrad P, Mahadevan-Jansen A. Optical stimulation of neural tissue in vivo. Optics Letters. 2005; 30(5):504-7. PMid:17526565 PMCid:1965456. http://dx.doi.org/10.1364/OL.30.000504

Wells JD, Thomsen S, Whitaker P, Jansen ED, Kao CC, Konrad PE, Mahadevan-Jansen A. Optically mediated nerve stimulation: Identification of injury thresholds. Lasers in Surgery and Medicine. 2007B; 39(6):513-26. PMid:17526565 PMCid:1965456. http://dx.doi.org/10.1002/1sm.20522

Wininger FA, Schei JL, Rector DM. Complete optical neurophysiology: toward optical stimulation and recording of neural tissue. Applied Optics. 2009; 48(10):218-24. PMid:17526565 PMCid:1965456. http://dx.doi.org/10.1364/ AO.48.00D218

Yanai HF, Yorimoto A, Kubota T, Fujii K, Kawaguchi F, Yamamoto E, Ichikawa N, Koshino Y. Observation on effect of optical stimulation to human using optical topography. Japanese Journal of Applied Physics. 2005; 44(8). PMid:17526565 PMCid:1965456. http://dx.doi.org/10.1143/ JJAP.44.6304

Yu NY, Chang SH. The Characterization of Contractile and Myoelectric Activities in Paralyzed Tibialis Anterior Post Electrically Elicited Muscle Fatigue. Artificial Organs. 2010; 34(4):E117-E21. PMid:17526565 
PMCid:1965456. http://dx.doi.org/10.1111/j.15251594.2009.00956.x

Zhang F, Gradinaru V, Adamantidis AR, Durand R, Airan RD, De Lecea L, Deisseroth K. Optogenetic interrogation of neural circuits: technology for probing mammalian brain structures. Nature Protocols. 2010; 5(3):439-56. PMid:17526565 PMCid:1965456. http://dx.doi.org/10.1038/nprot.2009.226
Zhang J, Laiwalla F, Kim JA, Urabe H, Wagenen RV, Song YK, Connors BW, Zhang F, Deisseroth K, Nurmikko AV. Integrated device for optical stimulation and spatiotemporal electrical recording of neural activity in light-sensitized brain tissue. Journal of Neural Engineering. 2009; 6:055007. PMid:17526565 PMCid:1965456. http://dx.doi. org/10.1088/1741-2560/6/5/055007

\section{Autores}

\section{Eddy Krueger*, Tiago Manczak}

Laboratório de Engenharia de Reabilitação, Pós-graduação em Engenharia Elétrica e Informática Industrial - CPGEI, Universidade Tecnológica Federal do Paraná - UTFPR, Curitiba, PR, Brasil.

\section{Edwing Martin Holguin Wilson}

Instituto de Cardiologia do Rio Grande do Sul, Porto Alegre, RS, Brasil.

\section{Wilson José da Silva}

Pós-graduação em Engenharia Elétrica e Informática Industrial - CPGEI,

Universidade Tecnológica Federal do Paraná - UTFPR, Curitiba, PR, Brasil.

\section{Percy Nohama}

Laboratório de Engenharia de Reabilitação, Pós-graduação em Engenharia Elétrica e Informática Industrial - CPGEI, Universidade Tecnológica Federal do Paraná - UTFPR, Curitiba, PR, Brasil.

Laboratório de Engenharia de Reabilitação, Pontifícia Universidade Católica do Paraná - PUCPR, Curitiba, PR, Brasil. 